\title{
Mais do que apenas dedos rápidos: narrativas e experiências de performances em League of Legends
}

\author{
Tarcízio Macedo ${ }^{1}$ \\ Manuela do Corral Vieira²
}

\begin{abstract}
Resumo: Este artigo procura discutir sobre uma performance de alto rendimento no jogo on-line League of Legends (LoL), cujo objetivo é compreender como a busca pela perícia ocorre entre os sujeitos-jogadores. Para tanto, o artigo concentra-se na discussão de um modelo binário composto pela mecânica e metagame no processo de especialização/aprendizado de uma experiência de cunho tanto operacional quanto social, passando pela repetição e a procura por padrões por parte dos jogadores. Para alcançar este objetivo, a proposta é formada de um processo articulado que possui nos elementos "jogo" e "jogadores" sua manifestação central para constituição da esfera empírica de investigação, a partir de um olhar baseado nos estudos da comunicação, performance studies e game studies. Nessa perspectiva, à guisa do método etnográfico, são apresentadas narrativas e experiências de performances em $L o L$ por jogadores das cidades de Belém (PA), Diadema (SP) e Osasco (SP). Os resultados apontam para as diversas capacidades que os aspectos sociais, para além do jogo, têm de incutir nas dinâmicas das narrativas e dos estudos das experiências, das perícias e das performances em $L o L$.
\end{abstract}

Palavras-chave: entretenimento digital; performance; mecânica; metagame; League of Legends.

\begin{abstract}
This article aims to discuss about high-performance on the online game League of Legends (LoL), which objective is to understand how the search for expertise occurs among players-subjects. In order to do so, this article focuses on the discussion of a binary model composed by mechanics and metagame, in the process of specialization/learning of an experience that is both operational and social, passing through repetition and the search for patterns on the part of the players. In order to reach this objective, is formed an proposal of an articulated process that has in the elements "game" and "players" its central manifestation for the constitution of the empirical sphere of investigation, based on communication studies, performance studies and game studies. In this perspective, according to an ethnographic method, narratives and experiences of performances on LoL
\end{abstract}

\footnotetext{
${ }^{1}$ Mestrando em Ciências da Comunicação pelo Programa de Pós-Graduação Comunicação, Cultura e Amazônia da Universidade Federal do Pará. E-mail: tarcizio.macedo@bol.com.br.

${ }_{2}^{2}$ Doutora em Antropologia pela Universidade Federal do Pará , mestre em Marketing pela Universidad Autónoma de Madrid e professora adjunta da Faculdade de Comunicação e do Programa de Pós-Graduação Comunicação, Cultura e Amazônia da UFPA. E-mail: manuelacorralv@yahoo.com.br.
} 
are presented by players from the cities of Belém (PA), Diadema (SP) and Osasco (SP). The results point to the various capacities that the social aspects, besides the game, have to instill in the dynamics of narratives and studies of experiences, expertises and performances in LoL.

Keywords: digital entertainment; performance; mechanics; metagame; League of Legends.

\section{Introdução}

A principal referência deste artigo consiste em traçar uma discussão sobre a noção de performance no jogo on-line competitivo League of Legends (LoL ou League). A pesquisa pretende discorrer sobre a busca pela perícia neste jogo e, portanto, é inerente a essa questão um processo de especialização/aprendizagem. Assim, a presente análise foca em uma camada de performance considerada de um tipo de alta produtividade/desempenho de jogabilidade 3 em League, mencionada nos estudos de Henry Lowood (2006), Michael Nitsche (2014) e Scott Donaldson (2015), cuja função é "ensinar-persuadir-convencer" o quão jogadores são bons.

Enquanto game competitivo, $L o L$ envolve a busca pela perícia, pela vitória, pelo conhecimento, pela habilidade e competência (PRZYBYLSKI; RIGBY; RYAN, 2010, p. 155-156), vencer e perder. Fundado pela desenvolvedora americana Riot Games, o alcance global de League ultrapassou a marca de 100 milhões de jogadores ativos mensalmente em 2016 e lidera o ranking de games on-line mais lucrativos4. Com a crescente ascensão de $L o L$ como o game mais popular do mundo, ele tem recebido ultimamente especial atenção no meio acadêmico por sua importância na cultura do jogo contemporâneo (DONALDSON, 2015, p. 3).

Este trabalho, portanto, concentra-se na discussão do processo de especialização de uma experiência de cunho tanto mais operacional quanto social, examinando dois tipos elementares de aprendizado em LoL, passando pelo sentimento de repetição e especialização procurado por certos jogadores. Trata-se de uma compreensão de elementos considerados tanto mais internos à gramática do jogo (FALCÃO, 2014, p. 46), suas regras e mecânicas, quanto mais externos, como o

${ }^{3}$ Segundo Katie Salen e Eric Zimmerman (2003), jogabilidade é a interação que ocorre entre jogadores e regras de um sistema formalizado por meio do jogo.

4Disponível em: <https://goo.gl/JL3Ss3 > e <https://goo.gl/DDdaG4>. Acesso em: 24 abr. 2017. 
metagame de LoL. O foco deste estudo é demonstrar as experiências de performances a partir de uma etnografia que busca contemplar as práticas dos jogadores deste jogo.

Neste sentido, o que queremos observar é a vertente de como o social é formulado e influencia em uma experiência considerada mais "técnico-operacional". Tomar as ações dos jogadores em $L o L$ como performance significa investigar, como sugere Richard Schechner (2013), o que as atitudes destes sujeitos representam, intencionam e, principalmente, como elas interagem com outros itens em jogo.

O texto apresentado divide-se em quatro seções: na primeira apresentamos as matrizes metodológicas que sustentam esta investigação, com objetivo de elucidar os pontos de partida da pesquisa; na segunda, alinhavamos questões pontuais sobre o conceito de performance, tanto na perspectiva dramatúrgica no campo dos performance studies quanto nos game studies; já as terceira e quarta seções abrangem, de modo específico, a análise que realizamos do processo de especialização de um tipo de performance de alto rendimento.

\section{O percurso metodológico}

A que se pese o objetivo desta pesquisa, uma análise que toma o jogo digital como objeto de estudo demanda do pesquisador metodologias específicas que devem adaptar-se aos requisitos que são por ele colocados. Compõe a perspectiva de Espen Aarseth $(1997,2003)$ o fato de que o jogar um jogo pressupõe um processo de aprendizagem e de uma hermenêutica dinâmica aplicada, na qual o "ir a campo" passa pela necessidade do experimentar o jogo assumindo a postura de um "usuáriojogador" (AARSETH, 2003, p. 19), uma vez que a apreensão dele passa, imprescindivelmente, pela necessidade de jogá-lo.

Desta forma, o trabalho de campo desta pesquisa foi concebido por meio de uma pesquisa etnográfica efetivada com sujeitos-jogadores de $L o L$. A seleção dos interlocutores desta pesquisa foi realizada após uma relação com os sujeitos entrevistados, sendo requisitado ao pesquisador participar de partidas com eles e aprender a explorar o universo do jogo. Com esse intento, foram selecionados quatro interlocutores que jogam ou jogaram League. Todos os participantes da pesquisa foram previamente informados sobre os objetivos dela e, para garantir a preservação 
das informações dos interlocutores, as informações obtidas neste artigo estão incluídas por nomes fictícios, sugeridos por alguns jogadores a partir dos nomes dos personagens no jogo que informaram mais gostar, que também se constitui em um exercício de leitura de performances.

À guisa do método etnográfico, a investigação foi conduzida por meio de um roteiro semiestruturado, construído com base em eixos de análise que focam em uma abordagem da performance. As entrevistas foram realizadas entre os meses de dezembro de 2016 a janeiro de 2017, com quatro informantes dentro de uma faixa etária dos 18 aos 26 anos, sendo dois deles (uma mulher e um homem) estudantes que vivem na cidade de Belém (PA), e outros dois (homens) estudantes que vivem nas cidades de Osasco (SP) e Diadema (SP).

\begin{tabular}{|c|c|c|c|}
\hline Jogador (a) & Idade & Tempo de LoL & Cidade \\
\hline Lulu & 23 anos & Joga há dois anos. & Belém/PA \\
\hline Jinx & 22 anos & $\begin{array}{c}\text { Jogou durante dois anos, parou } \\
\text { há quatro meses. }\end{array}$ & Diadema/SP \\
\hline Talon & 26 anos & Joga há três anos. & Osasco/SP \\
\hline Draven & 18 anos & Joga há três anos e meio. & \\
\hline
\end{tabular}

Tabela 1: Interlocutores

Fonte: Elaborado pelos autores

A pesquisa de campo dividiu-se em duas etapas: inicialmente, utilizamos de um perfil no jogo e na rede social on-line Facebook para contato com interlocutores. Em seguida, realizamos entrevistas semiestruturadas com dois participantes via chamada de vídeo, pelo aplicativo Skype, das cidades de Osasco (SP) e Diadema (SP) e outras duas, presencialmente, em Belém (PA). O campo, seguindo a característica intrínseca do próprio jogo on-line, possui uma dinâmica em rede.

\section{Pensar a performance, repensar o jogo/jogador}

Discutir sobre a noção de performance em games não é um pioneirismo, não somente porque o conceito é intensamente explorado no campo dos game studies a partir de variados aportes teóricos (cf. AARSETH, 2003; LOWOOD, 2006; 
PRZYBYLSKI; RIGBY; RYAN, 2010; NITSCHE, 2014; FALCÃO, 2014; DONALDSON, 2015; THOMAZ; CARDOSO FILHO, 2016; dentre outros), mas também porque articulações acerca desse fenômeno não são reservadas exclusivamente aos games.

Ao longo do tempo, e em diferentes contextos, o conceito de performance é carregado de múltiplos significados, e tornou-se popular em uma gama de atividades sociais (SCHECHNER, 2013; NITSCHE, 2014). A revisão colocada por Nitsche (2014) das performances nos games destaca essa mídia como um novo território emergente para performar, mostrando como a evolução da tecnologia ajudou a ampliar a gama de expressões para os meios digitais como performance. Por conseguinte, a organização social dos espaços circundantes é modificada rumo a um espaço de performance digitalmente realizado, que, em última análise, reposiciona o próprio jogador.

O ato de performance é compreendido, para Schechner (2013, p. 22), (i) em relação a ser, à existência em si mesma; (ii) fazer, ação de tudo que há; (iii) e mostrarse fazendo, logo, performar, deixar evidente e "demonstrar a ação". Schechner (2013, p. 32, tradução nossa) propõe uma teoria em que "qualquer comportamento, evento, ação, ou coisa pode ser estudado como se fosse performance e analisado em termos de ação, comportamento, exibição". Assim, essa noção de performance é muito útil como categoria analítica nos estudos dos games.

Nitsche (2014, p. 388, tradução nossa) afirma que, na origem do termo "performance", as mais diferentes abordagens compartilham um elemento central: "performance é sobre fazer", isto porque, para ele, "as performances crescem a partir do ato de se realizar". Para além da visão inicial de um evento encenado circunscrito ao teatro, a performance ganhou amplitude maior. Ela passa a incluir um amplo espectro de comportamentos e condições. Para Felippe Thomaz e Jorge Cardoso Filho (2016, p. 345), trilhando o percurso indicado por Schechner (2013), as performances tratam-se de comportamentos restaurados por meio dos quais os sujeitos agem (e reagem) ao ambiente, material e simbólico, em que estão inseridos.

Nos games, Nitsche (2014, p. 388) argumenta que a ideia de performance é geralmente utilizada para descrever eficácia, dominar um jogo ou as situações em um game com êxito. Schechner (2013, p. 22) afirma que, no contexto de esportes, 
negócios ou do sexo, dizer que determinado sujeito realizou uma "boa performance" significa afirmar que ele desenvolveu uma atividade conforme um alto padrão, que foi bem-sucedido e superou os demais e a si mesmo.

Não podemos olvidar que, em se tratando de um jogo do gênero de League, a busca por esse tipo de performance, pela perícia, seja um dos motivos que movam/moldam os jogadores. Em um editorial, publicado pela Riot Games em julho de 2014, Tom "Zileas" Cadwell, vice-presidente de game design da desenvolvedora, comentou que "o principal impulso que mantém os jogadores é a busca pela perícia (...). Jogar $L o L$ se trata de crescimento contínuo e tornar-se um jogador melhor"5. A partir disso, a filosofia de design em LoL está intimamente conectada com esta ideia: as performances dos jogadores.

Procurando entender algumas delas, propomos compreender uma camada que possui modos de comportamentos e atividades performáticas específicas e continuas. Trata-se de uma performance de "ensinar-persuadir-convencer" (SCHECHNER, 2013) fundamentada, a princípio, na aprendizagem técnica e nas estruturas definidas que orientam o jogo. Os jogadores, assim, aprendem jogando, isso porque eles se envolvem nessa prática de forma ativa (AARSETH, 2003, p. 19), interagindo com o artefato.

Tantos jogadores quanto designers, e até pesquisadores, referem-se ao processo de aquisição de perícia em games, especialmente o domínio dos controles, pelo termo de aprendizagem (PRZYBYLSKI; RIGBY; RYAN, 2010, p. 156; DONALDSON, 2015; AARSETH, 1997, 2003). Para Aarseth (2003, p. 15), há um processo de aprendizagem em todos os games, o que depende da interpretação desse processo por cada jogador, variando conforme as competências anteriores, o contexto e a motivação dele.

Para progredir ao longo das distintas etapas de aprendizado que existem no game, o jogador precisa explorar estratégias diversas e experimentar técnicas distintas (AARSETH, 2003, p. 19). Segundo Jinx, uma das interlocutoras desta pesquisa, a dinâmica de $L o L$ pressupõe o estudo da mecânica dos personagens, o

5 Disponível em: <https://goo.gl/P1MqIe> . Acesso em: 24 abr. 2017. 
estudo de builds ${ }^{6}$ e das constantes atualizações. Assim, como argumentado por Aarseth (2003, p. 19), jogar um jogo estabelece um processo de aprendizagem e de uma hermenêutica dinâmica aplicada pelo jogador. Para Lowood (2006, p. 26), uma performance de alto desempenho decorre das interrelações com o jogo, espectadores (incluindo jogadores) e virtuosismo técnico.

Para desenvolvimento desta pesquisa, seguimos os estudos de Peter Jakobsson, Daniel Pargman e Jana Rambusch (2007), Bryn Neuenschwander (2008) e Donaldson (2015) que propõem analisar a especialização em jogos multijogadores por meio de um modelo binário que compõe a perícia a partir do domínio de um jogador sobre os controles e as regras do jogo (perícia mecânica), em negociação com os contextos socioculturais mais amplos presentes em um game (perícia metagame ${ }^{7}$ ). As próximas duas seções procuram delinear aspectos usados dentro e fora do jogo pelos jogadores na busca por esses elementos binários.

À procura da perícia em League of Legends: práticas de performances

Segundo o processo de especialização de um jogo para Neuenschwander (2008, p. 190), inicialmente, em League, o jogador precisa acumular conhecimentos e aceitar as regras mecânicas que o rege. Em seguida, a segunda etapa envolve a compreensão das regras sociais, um consequente acompanhamento do metagame. Essa segunda forma de aprendizagem, segundo Donaldson (2015, p. 2), reporta-se a aspectos socioculturais contextuais. Isso significa, portanto, que jogadores exploram um conjunto de regras em um ambiente de possibilidades guiando as suas performances conforme o que é apresentado - e repetido - durante a dinâmica de LoL.

Assim, a repetição evidencia que, pela jogabilidade, jogadores podem aprender sobre os aspectos mecânicos e do metagame (cf. AARSETH, 2003). Deste modo, o próprio ato de jogar - repetir e reforçar, uma vez mais - implica uma espécie de

${ }^{6}$ Conjunto de itens utilizados para determinados personagens.

7Metagame ou metagaming refere-se ao "jogo além do jogo", a "relação entre o jogo e elementos externos, incluindo tudo, desde atitudes dos jogadores e estilos de jogo até reputações sociais e contextos sociais nos quais o jogo é jogado" (SALEN; ZIMMERMAN, 2003, p. 481, tradução nossa). Esse conceito reporta-se a aspectos do jogo que derivam da interação com contextos circundantes, e não das regras do jogo. 
“alfabetização" para a perícia, o que varia da interpretação do procedimento consoante ao jogador. Lulu, quando questionado sobre o porquê de jogar $L o L$, argumentou:

É um jogo que, ao mesmo tempo que parece ser repetitivo, nunca é igual. Porque tu estás sempre aprendendo, não só jogadas, mas como funciona aquele personagem ou como articular, fazer uma jogada [...], então eu acho que tu estás sempre evoluindo, pode parecer a mesma coisa [...], mas tem todo um processo que eu acho que nunca é igual. As pessoas não são iguais.

Assim, as performances em $L o L$ são dotadas de um potencial no aspecto operacional - ter habilidades, expertises mecânicas, conhecimento e o domínio das mecânicas/regras do jogo -, e logo, ser dotado do que Donaldson (2015, p. 2) chama de "perícia mecânica"8 e maestria com um personagem, mas também de uma dimensão social inerente, contextual, que influencia essa "experiência de cunho mais operacional" (FALCÃO, 2014, p. 46), sem a qual dificilmente um jogador conseguirá progredir no ambiente competitivo. A divisão binária de especialização é citada também no estudo de Jakobsson, Pargman e Rambusch (2007, p. 158) que compreende duas formas de possibilidades metodológicas de estudo e compreensão da jogabilidade.

De um lado, para os autores, existe a "manipulação do jogo" que concerne às atividades físicas e motoras de jogar um game. Por conseguinte, há uma atividade de criação de significados pelo jogador, ou seja, "o entendimento do game em termos de como ele deve ser jogado, do papel do jogador nele e a cultura ao entorno do jogo" (JAKOBSSON; PARGMAN; RAMBUSCH, 2007, 158, tradução nossa). De toda forma, ambos os elementos estão intimamente conectados (JAKOBSSON; PARGMAN; RAMBUSCH, 2007; DONALDSON, 2015).

Seguindo as perspectivas de Jakobsson, Pargman e Rambusch (2007) e Neuenschwander (2008), Donaldson (2015) divide a experiência da expertise em $L o L$ com base em dois elementos binários que definem a experiência de jogabilidade: (i) o primeiro é a experiência de perícia mecânica, que se reporta a elementos do jogo como o controle da interface e o conhecimento sobre as habilidades dos personagens;

${ }^{8}$ Domínio e conhecimento da mecânica do jogo, carácter máximo de aquisição de informação de um game (DONALDSON, 2015, p. 2). 
(ii) e o segundo é a competência e experiência da perícia do metagame, a consciência e capacidade de negociação entre o jogo e o seu contorno a partir de atualizações, uso de técnicas para determinar eficácia de itens ou combinações de personagens, análise de dados, uso de estratégias etc., ou seja, todas as "atividades que ligam o jogo a contextos externos" (SALEN; ZIMMERMAN, 2003, p. 482, tradução nossa).

Segundo Donaldson (2015, p. 2), a acumulação desses conhecimentos relacionados com o que é extrínseco à mecânica do jogo refere-se a um metagame, na opinião dele, uma segunda fase da experiência em LoL. Dentro da comunidade de $L o L$, este termo é usado para se referir a uma forma de como o jogo é jogado com base em quatro categorias: (1) o que os jogadores trazem a um jogo; (2) o que eles retiram do jogo; (3) o que acontece entre jogos; (4) o que acontece durante um jogo (cf. SALEN; ZIMMERMAN, 2003, p. 482). Embora não se possa considerar o metagame como "regra do jogo" em sentido formal, segundo Donaldon (2015, p. 11), a conformidade com as convenções nesse aspecto é considerada como a "etiqueta comportamental" de League, um manual a ser seguido e em constante transformação, as "regras dos jogadores" (THORHAUGE, 2013).

Estes conhecimentos seriam responsáveis por guiarem e "controlarem" a atividade dos jogadores em $L o L$, o que Aarseth (1997, p. 159, tradução nossa) chama de "netiqueta", "a etiqueta da rede, uma série de regras ou convenções para o comportamento" que, portanto, permite uma aproximação com o conceito de metagame. Segundo Aarseth, essas regras são formuladas, geralmente, por indivíduos que procuram impor um padrão determinado de comportamento polido às multidões variadas presentes na internet, na maioria dos casos com a pretensão de que essas regras constituídas reflitam as preferências e os desejos de uma maioria de utilizadores da rede - e dos jogos, neste caso (AARSETH, 1997, p. 159).

Para Anne Thorhauge (2013, p. 372), o que se refere como "as regras do jogo", normalmente, tratam-se de "convenções comunicativas aplicadas ao jogo pelos jogadores, enquanto que os comportamentos dos videogames representam outro tipo de fenômeno de regra" (THORHAUGE, 2013, p. 372, tradução nossa). Assim, mesmo que não se refira diretamente ao termo metagame, mas a uma noção de regras informais como Donaldson (2015), Thorhauge (2013, p. 388, tradução nossa) chega a 
uma compreensão muito próxima dele: "o significado de um jogo, sua essência, não é determinado pelas regras, mas pela forma como os jogadores se envolvem com essas regras".

Esse argumento é reforçado por Taylor (2011, p. 377, tradução nossa) para quem "as comunidades de jogadores criam novas regras e normas sobre como eles interagem com os sistemas de jogos". Assim, as regras do jogo não se tratam de um aspecto exclusivo ao artefato. Jinx, por exemplo, relatou uma experiência que reflete para as constantes atualizações existentes nas performances e, consequentemente, nos papeis dos jogadores a partir do metagame.

Gosto de jogar muito de Lulu de suporte, não sei se Lulu ainda está viável suporte [função em $L o L$ ], na época que eu estava jogando os picas das galáxias [jogadores-estrelas] do competitivo estavam começando a jogar de Lulu top [uma das rotas do jogo] também e aí... eu tive que começar a aprender a jogar de top, porque Lulu não era mais viável no mid, nem suporte, era só top... foi uma doidice.

Logo, o uso de determinados itens e personagens exige um nível de perfeição nessa repetição por conta da natureza que governa a ação no jogo, além de um nítido acompanhamento das atualizações dos padrões performáticos para cada papel presente em LoL. Podemos, assim, agrupar as formas extrínsecas de especializações de jogadores discutidas por Jakobsson, Pargman e Rambusch (2007), Neuenschwander (2008), Thorhauge (2013) e Donaldson (2015) como formas de conhecimento de metagame, que tanto são adquiridas quanto acumuladas a partir de um nível básico de conhecimentos mecânicos requisitados e necessários para a participação em uma equipe. A performance do jogador emerge, então, como pivô desses rearranjos, em que os contextos individuais promovem tensões com convenções comunicativas já socialmente estabelecidas no jogo - formadoras do que aqui se está chamando de metagame.

Visto in game, os itens disponíveis passam a serem incorporados no repertório cultural dos jogadores, emprestando uma dimensão técnica que compreende o treinamento, ou seja, o aprendizado e a destreza do uso de um item no jogo. Isso implica em um conjunto de transformações nas performances, como o próprio domínio dos dispositivos de controles do jogo (DONALDSON, 2015, p. 2), uma vez que "estímulos motores e cognitivos exigem competências específicas dos usuários e vice-versa" (THOMAZ; CARDOSO FILHO, 2016, p. 347, tradução nossa). 
Esse tipo de performance condensa um domínio dos aspectos de jogabilidade, da posse de itens e do uso adequado, em uma constante disputa por superioridade e domínio do sistema e da prática, e sua consequente repetição para alcançar tal fim. Neste processo de performance, os indivíduos procuram inserir valores que são amplamente reconhecidos pelos demais jogadores, formas de jogabilidade que já são legitimadas e que compõem o metagame do jogo. Draven, um dos interlocutores participantes deste estudo, afirmou que suas ações para compra de itens no jogo são influenciadas pelo que os outros pensarão sobre elas, portanto, ele afirmou procurar por sites, tutoriais, guias de builds ou mesmo itens recomendados para fundamentar suas escolhas de compra no jogo.

No intuito de auxiliar e acelerar a aquisição de experiência mecânica e do perfeito domínio operacional do jogo, e tirar vantagem disso, jogadores costumam acessar e usar elementos externos à jogabilidade, a fim de amplificarem a expertise e eficácia como jogador individual ou membro de equipe (DONALDSON, 2015, p. 8). Para além do processo inicial de acumulação de experiência, que envolve a tentativa e o erro de jogadores novatos na combinação de itens e personagens, eles costumam utilizar sites de terceiros, como o Mobafire9 (Figura 1), para acelerar sua aprendizagem, uma vez que os mecanismos embutidos no sistema de $L o L$ para a assistência e desenvolvimento de conhecimentos mecânicos, pelo menos no período de realização desta pesquisa, eram insuficientes e limitados para dar aos novos jogadores qualquer noção além de uma compreensão básica do gameplay a partir de um tutorial.

${ }^{9}$ Um site que funciona como uma comunidade e ferramenta de guias de estratégias sobre LoL, sendo alimentado pelos jogadores. Disponível em: <http://www.mobafire.com/>. Acesso em: 24 abr. 2017. 


\section{LUMINA}

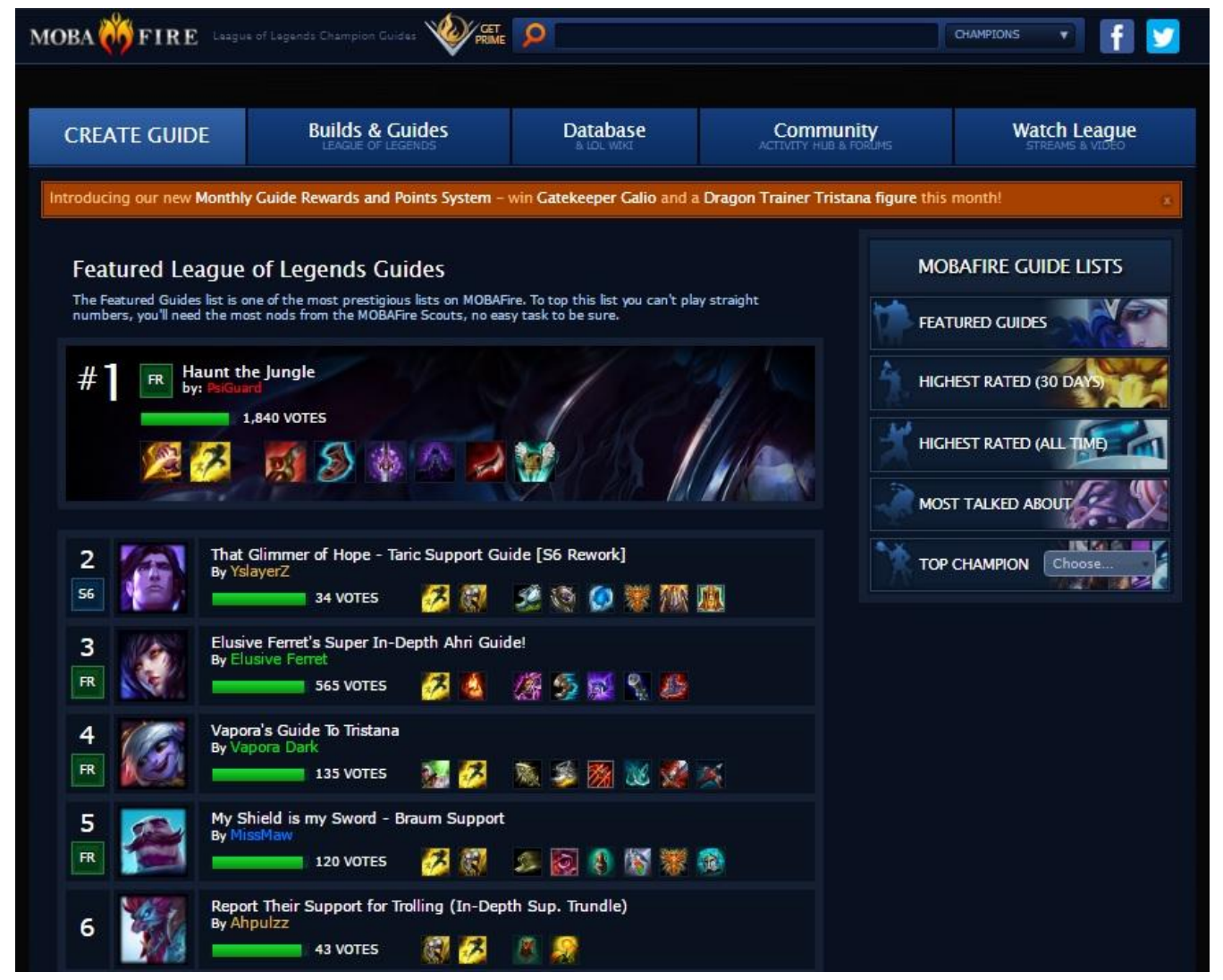

Figura 1: Guias em destaque de personagens de $L o L$ no Mobafire Fonte: Mobafire 


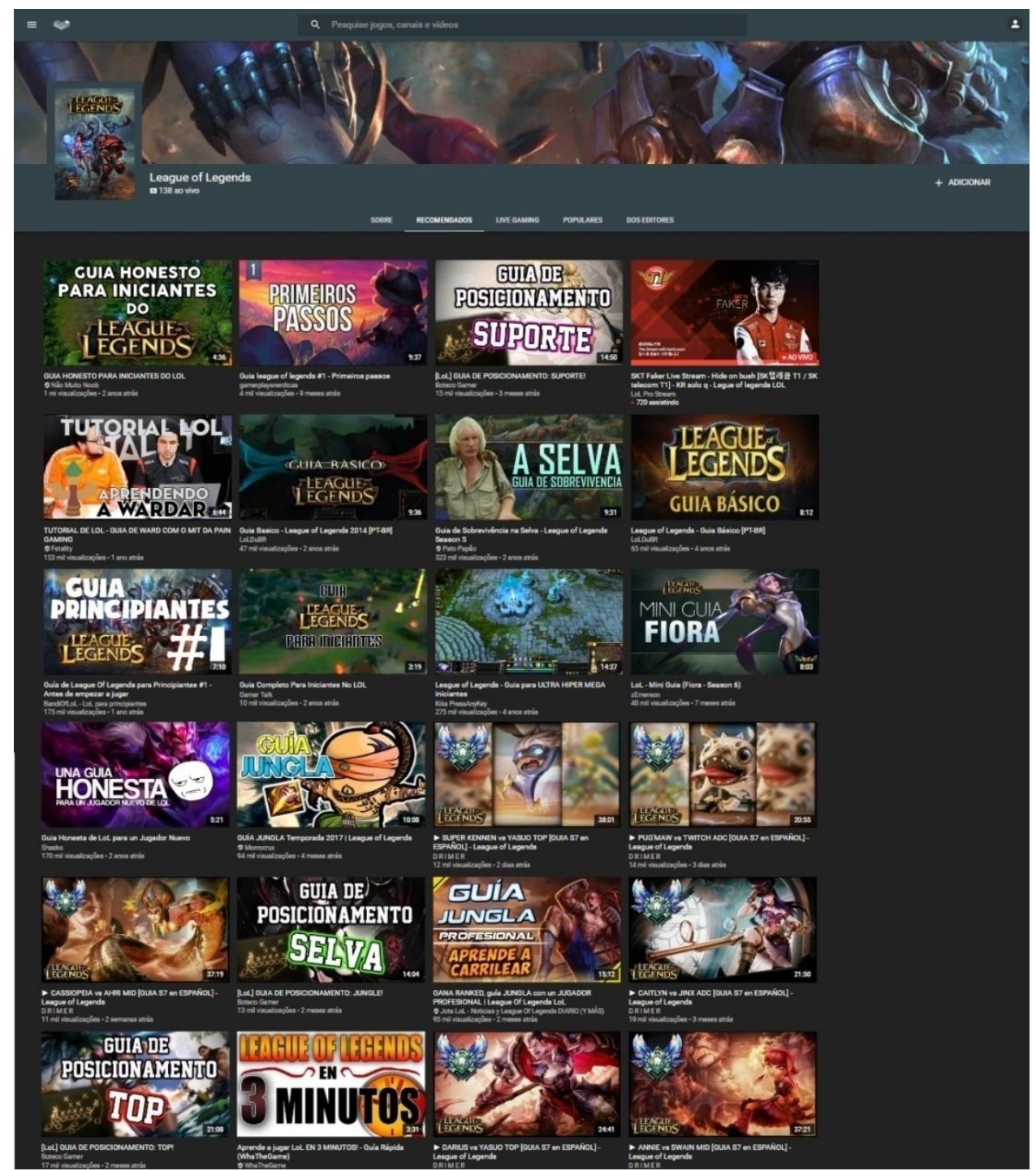

Figura 2: Séries de vídeos colaborativos de $L o L$ no YouTube Fonte: YouTube Gaming BR

Há, portanto, uma cultura da performance (Figura 2) baseada em vídeos criados por jogadores veteranos, que ensinam como e quando usar um personagem ou outro item, táticas e estratégias que auxiliam na resolução de objetivos mais complexos a serem conquistados (FALCÃO, 2014, p. 206). Taylor (2012, p. 92) argumenta igualmente que grande parte do tempo gasto por um jogador iniciante com um game é voltado para o aprendizado de como o sistema do jogo funciona. Quando iniciou em League, Lulu recebeu essa dica de sua irmã mais nova, que já conhecia o jogo:

[...] Ela falava assim: "é bacana tu sempre estar vendo [sic] os vídeos de youtubers para saber como que os personagens funcionam". Como eu não 
conhecia os nomes dos personagens e nem os personagens, eu ficava assistindo muito [...] Antes de comprar também um personagem [...], eu ia ver no YouTube como que ele funciona, o que que ele faz, como que as pessoas jogam. E aí, a partir disso, que eu comprava ele [sic], e eu treinava e jogava só com ele.

Para Lowood (2006, p. 26-30), a utilização desses vídeos possui um valor educativo, desde os primórdios em que as demonstrações de habilidades de "jogadores-estrelas" admirados e certificados de status passaram a ser usadas, comumente, por novos jogadores que desejavam obter melhores performances em um jogo a partir de gravações de um jogador mais qualificado, na esperança de que pudessem assimilar maneiras ou estratégias para melhorar suas habilidades, ajustando suas performances.

Essas séries colaborativas difundidas no You Tube e no Mobafire, e também populares em outros tipos de jogos on-line, têm o propósito de dar dicas de variados níveis sobre a mecânica e o metagame de LoL. Aliada a guias escritos, glossários, e até tutoriais em vídeos, estas são ferramentas que os jogadores podem utilizar para aumentar o conhecimento de como certos elementos do game podem interagir antes de ocorrerem no jogo. Consideramos esses sites capazes de potencializar a perícia mecânica e do metagame do jogo, apesar de Donaldson (2015) não deixar evidente esse processo, isto porque vídeos no You Tube não se limitam a ensinar uma expertise técnica, mas também regras sociais do jogo que não estão circunscritas somente em fóruns ou comunidades, como pensa Donaldson (2015, p. 8-10).

Saber combar $^{10}$ com um personagem exige esse processo de aprendizado, segundo Draven, bem como acompanhar as atualizações das builds em sites, guias e tutorias. Jinx e Lulu, por exemplo, argumentam para a necessidade de terem que aprender a jogar com personagens só porque ganharam skins ${ }^{11}$ para eles. Logo, por conta das relações associadas ao uso de skins à perícia, jogadores são motivados a treinarem com personagens não habituais, no intuito de satisfazerem e corresponderem às expectativas cobradas. Isso demonstra, como apresenta

\footnotetext{
${ }^{10}$ Combinação sequencial de habilidades de um personagem por meio de rápidos clicks de botões em um teclado/mouse em um determinado espaço de tempo.

${ }^{11}$ São designs customizados com transformações estéticas de personagens dentro do ambiente de LoL (cf. MACEDO; AMARAL FILHO, 2015).
} 
Donaldson (2015, p. 3, tradução nossa), a existência de um metagame local, talvez temporário, que "exige do jogador uma forma de conhecimento relacionado a elementos separados da mecânica do jogo”.

Em LoL, uma skin confere ao seu portador credibilidade de alguém capaz de desempenhar uma performance "boa", sinônimo de perícia. A transferência desse status ao jogador dá a ele, segundo evidenciado por todos os informantes, maior confiança em suas performances no início do jogo, como nos mostra Draven:

Outra coisa que as skins ajudam é que te dá um pouco de confiança [...]. Você se sente um pouco exclusivo, superior, isso te dá uma confiança a mais, às vezes pode ajudar no jogo, você se sente mais solto, joga mais na calma, pensa mais para jogar. Você está ali tranquilo, te dá um título, o cara pensa que você joga muito bem com aquele personagem se tem uma skin boa.

Para os interlocutores, usar uma skin consistia em adereço importante na performance em jogo, capaz de impactar na maneira como agiam, seja quando usavam ou quando viam algum adversário usando. Jinx ressaltou que, no momento em que ela via alguém que seria seu adversário nas fases de rotas iniciais trajando uma skin, automaticamente ela procurava comprar itens defensivos ao invés de itens de ataque. Isso denota que, ao passo que esse tipo de item proporciona determinadas "vantagens" no jogo, podendo ajudar jogadores, dando-lhes mais confiança e causando uma primeira impressão positiva, interferindo nas performances dos adversários (conforme afirmaram os jogadores entrevistados), há uma série de expectativas que pertencem à autonomia dos itens em $L o L$.

Essa ideia associada ao uso de skins em LoL é um elemento externo apropriado pela comunidade de jogadores, sendo parte do metagame. Essa dinâmica reforça que os jogadores, na busca pelo seu sucesso competitivo, devem adquirir ao menos algum nível social para que possam progredir em determinados momentos de LoL. Temos, logo, uma relação de cultivo à reputação, à perícia, ao domínio de um personagem intimamente ligado com o uso da skin. 


\section{Seguindo exemplos, construindo trajetórias: repetição e comportamento restaurado em League}

Presente nos games, a repetição é uma "velha conhecida" (FALCÃO, 2014, p. 203). Donaldson (2015, p. 6), por exemplo, argumenta que jogadores novatos de games competitivos on-line usam de recursos externos e experiências anteriores para construírem a perícia. Assim sendo, "não há nenhuma ação humana que possa ser classificada como um comportamento exercido uma única vez" (SCHECHNER, 2013, p. 23, tradução nossa).

Como vimos anteriormente, Lulu nos mostra o quanto as performances praticadas nos games são formadas por comportamentos restaurados, duplamente realizados, ações performadas que são treinadas para serem desempenhadas, que pressupõem um processo de repetição e ensaio (SCHECHER, 2013, p. 22). Tal como em outros jogos, a repetição é relevante em $L o L$ em uma série de aspectos, pois tratase de um mediador poderoso de relações sociais entre jogadores (FALCÃO, 2014, p. 203). A prática de repetir, do jogar de novo, proporciona a um jogador ultrapassar o status de um noob, "o jogador novato, de quem se zomba, por não conhecer as possibilidades do jogo" (FALCÃO, 2014, p. 203), rumo ao status de jogador exímio e, em alguns casos, profissional.

As performances são realizadas a partir dos fragmentos de comportamentos restaurados, mas ao mesmo tempo cada performance é distinta das outras, como percebemos em fala anterior de Lulu. Segundo Schechner (2013, p. 23), nenhum evento é igualmente como outro, ou pode copiá-lo. Assim, "toda e qualquer performance é específica e diferente de todas as outras" (SCHECHNER, 2013, p. 29, tradução nossa). Embora o sistema do jogo permaneça, o contexto de cada recepção dele é, portanto, diferenciado em várias instâncias. "Em outras palavras, a particularidade de um dado evento está não apenas em sua materialidade, mas em sua interatividade" (SCHECHNER, 2013, p. 23, tradução nossa). Estas interpretações foram igualmente percebidas nas falas de Lulu e de Draven, sendo destacado por este que "mesmo que o jogo seja a mesma coisa sempre, derrubar torres, fazer dragões, matar seus inimigos, ajudar o time, nunca uma partida é igual a outra, sempre uma partida é diferente da outra". 
Segundo Thiago Falcão (2014, p. 205), seriam essas repetições responsáveis pela garantia, manutenção e legitimação de determinados tipos de performances em jogo. Ao se introduzirem novas maneiras alternativas de agir, as performances estão passíveis de sofrerem mudanças, como nos mostraram Jinx e Lulu (cf. p. 10, 14).

Jinx relata uma experiência que caminha neste sentido, ao perceber a dimensão da repetição e imitação, do quanto os comportamentos em $L o L$ são duplamente exercidos ou restaurados, a partir das ações de determinados jogadoresestrelas, aspecto também relatado por Lulu (cf. p. 14). Neste caso, Jinx nos diz que quando um jogador respeitado na comunidade, que pertença a um time reconhecido, passa a utilizar personagens antigos ou novos, até mesmo em funções diferentes das estabelecidas pelo metagame, outros jogadores passam a repetir esses comportamentos.

Eu acho que tem uma coisa no $L o L$ que as pessoas tentam imitar sempre quem está no topo dos jogos profissionais [...] E aí quando um jogador em ascensão passa a ganhar os jogos com personagens diferentes, que as pessoas não jogam muito, [...] [elas] tentavam imitar os caras que estavam jogando no profissional.

Assim, as performances são atualizadas na medida em que jogo, metagame e jogadores também o são, o que significa pensar que a melhor forma de compreender LoL é pelo estado de fluxo (DONALDSON, 2015, p. 11). Nada é muito fixo nessas categorias performáticas; segundo Schechner (2013, p. 30), novas camadas costumam emergir enquanto outras caem no desuso.

Desta forma, a repetição é essencial para o domínio do jogo pelo jogador, assim como a reencenação das ações em $L o L$ é primordial para sua manutenção enquanto produto midiático que depende de uma receita para se manter (FALCÃO, 2014, p. 205-206). Desta forma, a repetição é relevante para que um jogador possa compreender um jogo, ela é essencial para que ele possa dominá-lo com maestria. "Tal maestria é o resultado do retorno: de novo, e de novo, e de novo, até que nuances mínimas relacionadas se desvelam" (FALCÃO, 2014, p. 203-204).

Em uma partida em $L o L$, exige-se dos sujeitos, das próprias máquinas e até dos sistemas do jogo que desempenhem "boas" performances. O espaço da performance, então, não ocorre somente no jogo, mas na ação, relação e interação 
deste com elementos exteriores, uma vez que são nas conexões com esses contextos socioculturais distintos que a experiência tecnolúdica ocorre.

\section{Conclusão}

Este artigo buscou seguir uma trilha teórica que sustenta a compreensão do fenômeno da performance no jogo competitivo on-line League of Legends como um processo que promove uma experiência de cunho mais operacional e indissociável de contextos sociais mais amplos, que tanto legitimam a "boa" performance quanto estabelecem os padrões que são mais aceitáveis em jogo. Por meio de um estudo etnográfico, procuramos demonstrar as diversas capacidades que os aspectos sociais do jogo, que derivam da interação com contextos circundantes, têm de incutir nas dinâmicas da perícia em LoL. Assim, não basta aos jogadores terem o pleno domínio das mecânicas e dos controles, neste sentido, serem rápidos nos dedos, se não adquirirem ao menos um nível social necessário para que possam progredir e serem eficazes no ambiente competitivo, especialmente em níveis mais elevados.

O que se buscou analisar ao longo deste estudo é que jogadores de $L o L$ atuam/performam de distintas maneiras, mas igualmente se baseiam na busca pela perícia. Nesse percurso, argumentamos para um processo de especialização dos jogadores baseado em um modelo binário que compõe a experiência de perícia mecânica, de um lado, e na competência da perícia do metagame de outro. Assim, jogar LoL incorpora uma dinâmica que demanda uma dupla aprendizagem: a aquisição de conhecimentos e habilidades mecânicas, prática e repetição, o retorno cuja "a necessidade de definir-se através do padrão" (FALCÃO, 2014, p. 237) é inerente de um tecido social contextual exterior, no qual o jogo também se desenvolve, que influencia as performances técnicas-operacionais-mecânicas, no domínio dos controles. Em seguida, discutimos sobre a repetição, e como padrões são recuperados e emergem nessa cultura performática de $L o L$ ao longo do tempo. Destacamos, portanto, que as formas de perícia fora do jogo, ou metagame, são de particular relevância para League.

Entretanto, há muitos modos de compreender as performances em games. O uso deste conceito é tanto vantajoso quanto interessante para se questionar uma série de dimensões sociais presentes nessa mídia. Pensar tanto no jogo como nas 
performances que abundam na vida cotidiana, neste senso da onipresença enfatizado pelo ambiente midiatizado em que vivemos, é saber que ambos - o jogar e a performance - fundamentam-se nas ações dos sujeitos e, neste sentido, a performance fornece uma maneira de olhar rica para a interpretação e desenvolvimento da cultura presente nos jogos e entretenimentos digitais.

\section{Referências}

AARSETH, Espen. O Jogo da Investigação: abordagens metodológicas à análise de jogos. In Caleidoscópio, n. 4, 2003, p. 9-23.

AARSETH, Espen. Cybertext: Perspectives on Ergodic Literature. London/Baltimore: The Johns Hopkins University Press, 1997.

DONALDSON, Scott. Mechanics and Metagame: Exploring Binary Expertise in League of Legends. In Games and Culture, online first, 2015, p. 1-19.

FALCÃO, Thiago. Não humanos em Jogo. Agência e Prescrição em World of Warcraft. Tese (Doutorado em Comunicação e Cultura Contemporâneas). Universidade Federal da Bahia, Salvador, 2014.

JAKOBSSON, Peter; PARGMAN, Daniel; RAMBUSCH, Jana. Exploring E-sports: a case study of gameplay in counter-strike. In: Proceedings of DiGRA

International Conference, 2007, Tokyo. Annual International Conference of DiGRA, 2007, v. 4, p. 157-164.

LOWOOD, Henry. High-performance play: The making of machinima. In Journal of Media Practice, v. 7, n. 1, 2006, p. 25-42.

MACEDO; Tarcízio; AMARAL FILHO, Otacílio. Dos rios à tela de cristal líquido: o retorno do mito e a arquitetura da cultura convergente em League of Legends. In Revista Fronteiras: estudos midiáticos, São Leopoldo, v. 17, n. 2, p. 231-247, maio/ago. 2015. Doi: http://dx.doi.org/10.4013/fem.2015.172.10

NEUENSCHWANDER, Bryn. Playing by the rules: Instruction and acculturation in role-playing games. E-Learning and Digital Media, v. 5, n. 2, 2008, p.189198.

NITSCHE, Michael. Performance. In: The Routledge Companion of Video Game Studies. WOLF, Mark; PERRON, Bernard. (Ed.). New York: Routledge, 2014, p. 388-396.

PRZYBYLSKI, Andrew; RIGBY, Scott; RYAN, Richard. A motivational model of video game engagement. Review of General Psychology, v. 14, n. 2, 2010, p. 154166.

SALEN, Katie; ZIMMERMAN, Eric. Rules of Play: Game Design Fundamentals. Cambridge/MA: MIT Press, 2003.

SCHECHNER, Richard. Performance studies: an introduction. 3 ed. New York: Routledge, 2013. 
TAYLOR, T. Raising the Stakes: E-Sports and the Professionalization of Computer Gaming. Cambridge/MA: MIT Press, 2012.

TAYLOR, T. Internet and Games. In: CONSALVO, Mia; ESS, Charles. (Ed.). The Handbook of Internet Studies. UK: John Wiley and Sons, 2011, p. 369-383.

THOMAZ, Felippe; CARDOSO FILHO, Jorge. Playful Experiments: Conditions of "An Experience" in Touchscreen Games by a Non-Hermeneutic Perspective. In: VALENTINE, Keri; JENSEN, Lucas (Ed.). Examining the Evolution of Gaming and Its Impact on Social, Cultural, and Political Perspectives. Hershey/Pennsylvania: IGI Global, 2016, p. 343-363.

THORHAUGE, Anne. The Rules of the Game - The Rules of the Player. Games and Culture, v. 8, n. 6, 2013, p. $371-391$. 